\title{
The Hiccup: a dynamical coupling process during the autumn transition in the Northern Hemisphere - similarities and differences to sudden stratospheric warmings
}

\author{
V. Matthias ${ }^{1}$, T. G. Shepherd ${ }^{2}$, P. Hoffmann ${ }^{1}$, and M. Rapp ${ }^{3,4}$ \\ ${ }^{1}$ Leibniz Institute of Atmospheric Physics at the University of Rostock, Kühlungsborn, Germany \\ ${ }^{2}$ Department of Meteorology at the University of Reading, Reading, UK \\ ${ }^{3}$ Deutsches Zentrum für Luft- und Raumfahrt, Institut für Physik der Atmosphäre, Oberpfaffenhofen, Germany \\ ${ }^{4}$ Meteorologisches Institut München, Ludwig-Maximilian Universität München, Munich, Germany \\ Correspondence to: V. Matthias (matthias@iap-kborn.de)
}

Received: 9 October 2014 - Revised: 21 January 2015 - Accepted: 26 January 2015 - Published: 23 February 2015

\begin{abstract}
Sudden stratospheric warmings (SSWs) are the most prominent vertical coupling process in the middle atmosphere, which occur during winter and are caused by the interaction of planetary waves (PWs) with the zonal mean flow. Vertical coupling has also been identified during the equinox transitions, and is similarly associated with PWs. We argue that there is a characteristic aspect of the autumn transition in northern high latitudes, which we call the "hiccup", and which acts like a "mini SSW", i.e. like a small minor warming. We study the average characteristics of the hiccup based on a superimposed epoch analysis using a nudged version of the Canadian Middle Atmosphere Model, representing 30 years of historical data. Hiccups can be identified in about half the years studied. The mesospheric zonal wind results are compared to radar observations over Andenes $\left(69^{\circ} \mathrm{N}\right.$, $16^{\circ} \mathrm{E}$ ) for the years 2000-2013. A comparison of the average characteristics of hiccups and SSWs shows both similarities and differences between the two vertical coupling processes.
\end{abstract}

Keywords. Meteorology and atmospheric dynamics (general circulation; middle atmosphere dynamics; waves and tides)

\section{Introduction}

Dynamical stratosphere-mesosphere coupling can be caused by gravity waves (GWs), tides and planetary waves (PWs), and strongly influences the dynamics of the middle atmosphere (e.g. Miyahara et al., 1993; Holton and Alexander,
2000). The most impressive and prominent vertical coupling process in the middle atmosphere is the sudden stratospheric warming (SSW), which occurs primarily in the Northern Hemisphere winter and is caused by the interaction of PWs with the mean flow (e.g. Matsuno, 1971; Andrews et al., 1987). SSWs are characterised by a rapid increase of the stratospheric polar temperature by up to $80 \mathrm{~K}$ with a simultaneous decrease of the mesospheric polar temperature by up to $30 \mathrm{~K}$, along with a wind reversal/weakening of the zonal mean zonal wind in the middle atmosphere (e.g. Charlton and Polvani, 2007; Matthias et al., 2012). The mesospheric cooling is understood to be caused by anomalous upwelling driven by anomalous filtering of GW fluxes (e.g. Holton, 1983; Ren et al., 2008), although anomalous upwelling from the PW drag also contributes in the lower mesosphere (e.g. Ren et al., 2008).

Strong vertical coupling has also been identified during the equinox transitions between the easterly zonal flow, which characterises the summer half of the year, and the westerly flow, which characterises the winter half. Distinctive "sawtooth" mesospheric temperature and airglow enhancements, which pointed to circulation anomalies, were identified during the Northern Hemisphere spring transition by Stegman et al. (1992) and G. G. Shepherd et al. (1999). Their association with the final stratospheric warming was noted by M. G. Shepherd et al. (2002), pointing to the importance of vertical coupling. A similar (but opposite signed) "sawtooth" (or "V-shaped") variability was identified in the autumn transition by Taylor et al. (2001) using local lidar measurements 

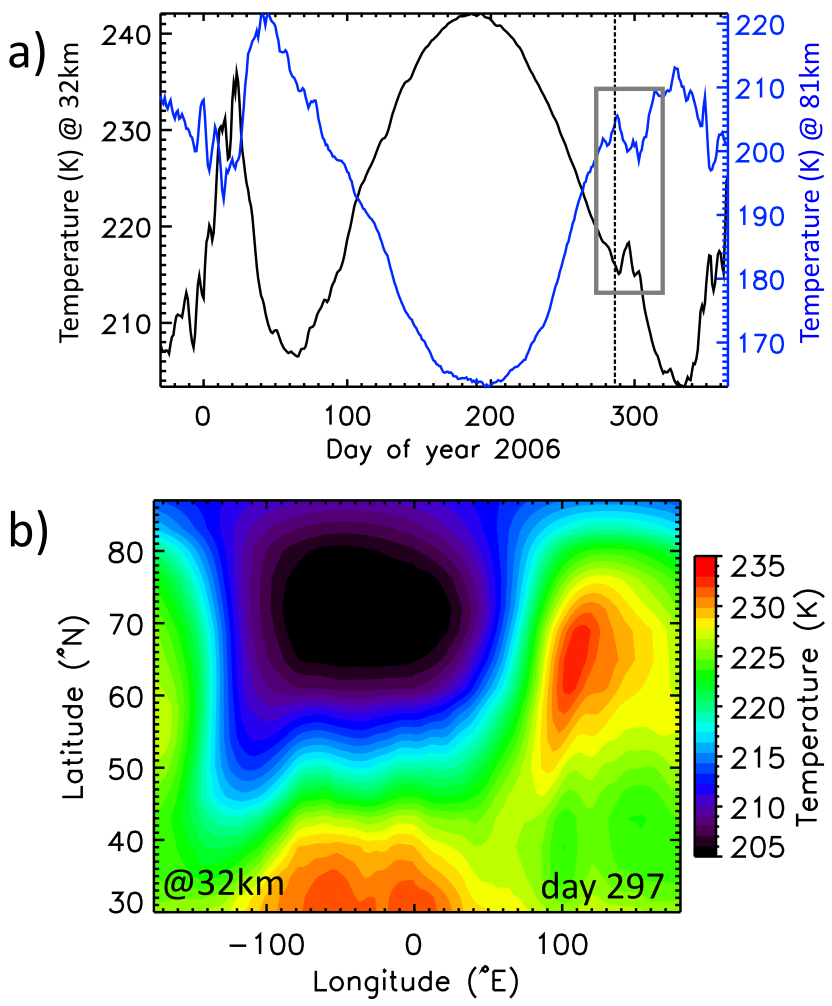

Figure 1. (a) Seasonal variation of the zonal mean temperature at $32 \mathrm{~km}$ (black) and $81 \mathrm{~km}$ (blue) averaged between 65 and $75^{\circ} \mathrm{N}$ over the year 2006. The vertical dashed line marks the hiccup onset day. (b) Temperature pattern as a function of longitude and latitude on day 297 of 2006, the local peak of the temperature at $32 \mathrm{~km}$ in (a). The data are derived from the CMAM30 data set (see text).

at mid latitudes, and by M. G. Shepherd et al. (2004) using global satellite observations from WINDII. G. G. Shepherd et al. (2004) suggested that the two equinox transitions should be treated as related phenomena.

Based on TIME-GCM simulations, Liu et al. (2001) argued that the variability in the autumn transition resulted from enhanced vertical propagation of stationary PWs (SPWs) into the mesosphere, expected during the weak (but rapidly changing) zonal winds characteristic of that time. The same mechanism would obviously apply to the spring transition. However, enhanced SPW amplitudes on their own would induce temperature perturbations of opposite sign at different longitudes, and M. G. Shepherd et al. (2004) showed that the zonal mean temperature also exhibited a "V-shaped" cooling during the autumn transition at $87 \mathrm{~km}$. Since enhanced SPW propagation into the mesosphere would be expected to lead to enhanced polar descent and hence to warming, it seems likely that more than PW propagation is involved.

During the autumn transition, the zonal wind reversal from easterlies to westerlies allows the onset of SPW propagation into the middle atmosphere (Charney and Drazin, 1961). If some of this SPW activity dissipates in the stratosphere, it would result in stratospheric polar downwelling and warming, which would weaken the zonal wind, somewhat like a mini SSW, i.e. like a small minor warming regarding the strength of the wind weakening. Thus, one might generally expect a sudden weakening of the zonal wind (and stratospheric polar warming) as SPW propagation switches on, before the wind resumes its strengthening as part of the overall autumn transition. We call such behaviour a "hiccup" in the autumn transition. Just as with SSWs, we may expect a concomitant, and largely synchronous, mesospheric zonal-mean "hiccup" of opposite sign in temperature, as a result of PW and GW induced polar upwelling (e.g. Siskind et al., 2005; Ren et al., 2008). The phenomenon is evident in the grey rectangle in Fig. 1a, which shows the seasonal variation of the zonal mean temperature around $70^{\circ} \mathrm{N}$ at $32 \mathrm{~km}$ (black) and $81 \mathrm{~km}$ (blue) for 2006. Figure $1 \mathrm{~b}$ confirms that there is a prominent wave- 1 feature at $32 \mathrm{~km}$ on day 297 , when the peak 32-km temperature during the hiccup in Fig. 1a is observed.

In principle, the same process might be expected to be operative in the spring transition, where the sudden cessation of SPW propagation as the zonal winds weaken would turn off the stratospheric polar downwelling, allowing the zonal winds to suddenly strengthen before continuing their transition towards summertime easterlies. The stratospheric and mesospheric temperature anomalies in this case would be opposite in sign to those in the autumn "hiccup", consistent with the mesospheric observations of M. G. Shepherd et al. (2002). However, the spring transition is much more variable than the autumn transition, because it occurs within an already disturbed environment, due to the high level of wave activity in the winter and spring (e.g. Wunch et al., 2005; Manson et al., 2002). These disturbances of the background wind make it hard to set the hiccup onset day. So the effect should be more easily detectable in the autumn transition where it is proceeding from the quiescent summertime state.

The goal of this study is to examine the morphology of the stratosphere-mesosphere coupling during the "hiccup" in the autumn transition using a new model data set, which provides an estimate of the stratospheric and mesospheric daily state over the last 30 years. We focus on the average characteristics of the hiccup over the polar cap $\left(60-90^{\circ} \mathrm{N}\right)$, which is the latitude range where the hiccup appears to be strongest (cf. Fig. 1b). Although the hiccup is manifest in zonal-mean fields, we also want to see whether it might explain at least some of the behaviour seen at particular longitudes (e.g. Taylor et al., 2001). We use 30 years of historical data (19792010) of the nudged Canadian Middle Atmosphere Model CMAM30 and compare the wind results in the mesosphere with 14 years of local radar measurements (2000-2013) in Andenes $\left(69^{\circ} \mathrm{N}, 16^{\circ} \mathrm{E}\right)$.

This paper is structured as follows. The next section provides an overview of the CMAM30 model simulation and a short specification of the radar measurements used in this 
Table 1. Hiccup onset days of the hiccup-years, from 1979 to 2013.

\begin{tabular}{cc}
\hline Year & Hiccup onset day \\
\hline 1979 & 295 \\
1980 & 284 \\
1984 & 284 \\
1985 & 294 \\
1988 & 287 \\
1990 & 288 \\
1991 & 301 \\
1992 & 305 \\
1994 & 305 \\
1996 & 296 \\
1998 & 294 \\
2003 & 275 \\
2004 & 284 \\
2005 & 285 \\
2006 & 285 \\
2008 & 299 \\
2009 & 278 \\
2010 & 297 \\
2013 & 283
\end{tabular}

study, as well as a description of the analysis method. The results of the superimposed epoch analysis are shown in Sect. 3 and discussed in Sect. 4. Section 5 provides a summary of the results.

\section{Data and analysis}

To study the average characteristics of wind, temperature and PW 1 during the hiccup, the nudged version of the Canadian Middle Atmosphere Model (CMAM) is used (de Grandpré et al., 2000; Scinocca et al., 2008; McLandress et al., 2013). The model domain extends from 1000 to $0.008 \mathrm{hPa}$ $(0-100 \mathrm{~km})$ with a vertical resolution of better than $1 \mathrm{~km}$ in the troposphere and $2.5 \mathrm{~km}$ in the mesosphere, and a horizontal resolution of $3.75^{\circ}$ in latitude and longitude. However, the upper levels of the model will be contaminated by the sponge layer and the data above about $85 \mathrm{~km}$ are probably not reliable. The data analysed here have a temporal resolution of $6 \mathrm{~h}$, and daily mean values are used for this study to avoid tidal impact. In this nudged configuration, the horizontal winds and temperatures are nudged to ERA-Interim below $1 \mathrm{hPa}$, and it is a free running model above. The resulting data set, which covers the 30-year period 1979-2010, is known as the CMAM30 data set. Constraining the dynamical state of the troposphere and stratosphere allows information to propagate up into the mesosphere through both PWs and parameterised GW fluxes, which strongly constrains the large-scale state of the mesosphere (Ren et al., 2008). McLandress et al. (2013) show that the CMAM30 data are in good agreement with MLS satellite observations in the mesosphere during the several extended winters studied. Thus, CMAM30 data pro-

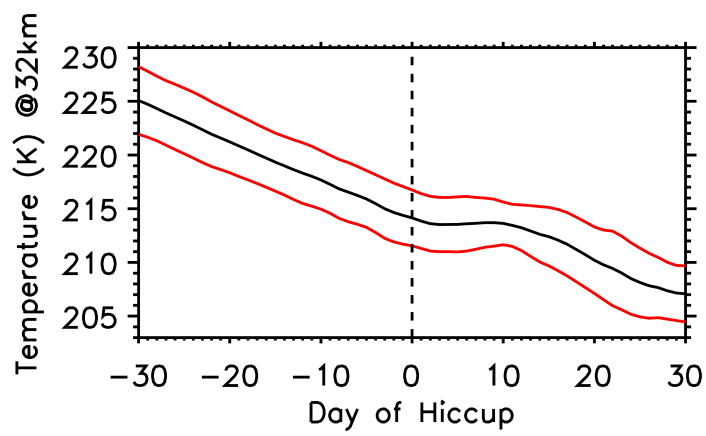

Figure 2. Zonal mean temperature variation (black) and its standard deviation (red) at $32 \mathrm{~km}$ averaged between 65 and $75^{\circ} \mathrm{N}$, averaged over all hiccups. The data are derived from CMAM30 for events occurring from 1979 to 2010, and from MERRA for events occurring from 2011 to 2013 .

vide a good basis to study vertical coupling processes from the troposphere up to the mesosphere, and compare directly with observations over a long time period. The data are available from: http://www.cccma.ec.gc.ca/data/cmam/cmam30/ index.shtml.

To corroborate the model results in the mesosphere, wind measurements of a mid-frequency (MF) radar in Andenes $\left(69^{\circ} \mathrm{N}, 16^{\circ} \mathrm{E}\right)$ are used. The MF radar operates at $1.98 \mathrm{MHz}$ with a peak power of $40 \mathrm{~kW}$ applying the spaced antenna technique (Singer et al., 1997). Horizontal winds have been continuously derived between 80 and $98 \mathrm{~km}$ since the year 2000 using the full correlation analysis method. Prevailing winds are obtained by subtracting terdiurnal, semidiurnal and diurnal tides using a least squares fit of hourly winds for a 4day interval shifted by 1 day.

In order to apply the superimposed epoch analysis, we have to define what is meant by a hiccup, and an onset day. Motivated by Fig. 1a, the hiccup onset day is defined as the first day in each autumn where at $10 \mathrm{hPa}$ and at $70^{\circ} \mathrm{N}$ :

1. the zonal mean zonal wind is larger than $15 \mathrm{~m} \mathrm{~s}^{-1}$,

2. $\mathrm{d} u / \mathrm{d} t<0$ for at least 5 days, and

3. the mean zonal wind subsequently increases above the value that was maximally reached before the hiccup.

The first condition is chosen because SPWs can only propagate into the middle atmosphere if the zonal wind is larger than about $15 \mathrm{~m} \mathrm{~s}^{-1}$ (Nash et al., 1996). The second condition ensures a sufficiently discernible hiccup. The third condition limits the events to the autumn transition. Based on these criteria, a hiccup was found to occur in 19 out of the last 35 years (see Table 1), i.e. it occurs on average every second year. Thus, the composites of the CMAM30 data include 18 events, while those of the radar data includes eight events. Note that from 2011 to 2013 MERRA data (e.g. Rienecker et al., 2011) were used to estimate the hiccup onset day, since the CMAM30 data only cover up to 2010 . Figure 2 shows the 


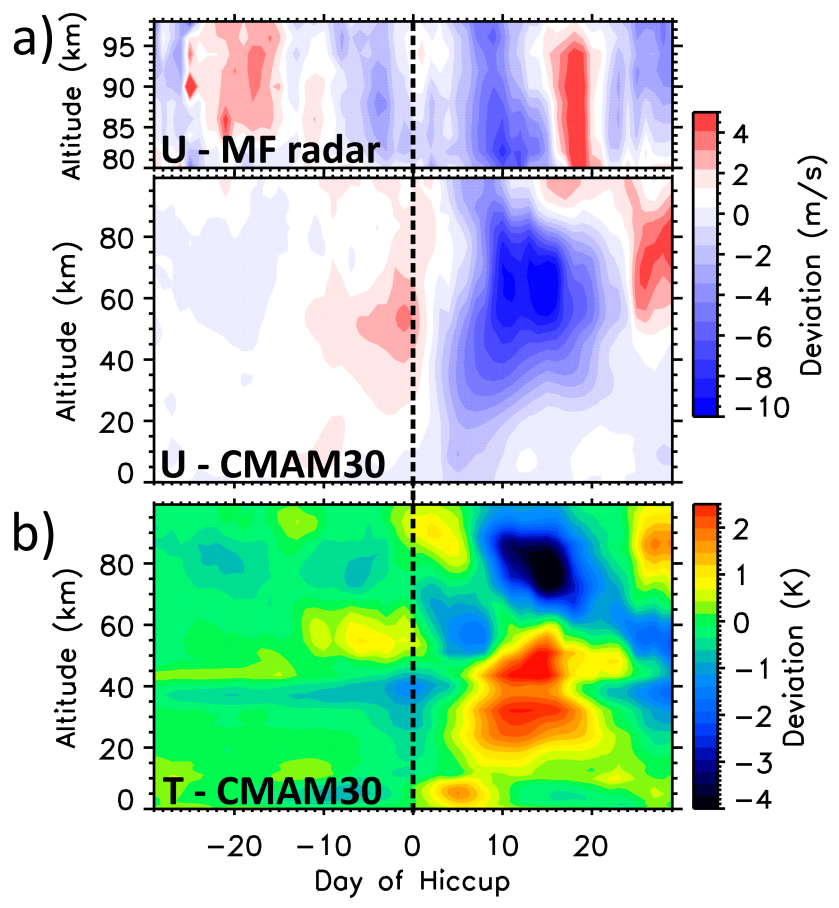

Figure 3. (a) Hiccup composite of the zonal wind anomaly at Andenes $\left(69^{\circ} \mathrm{N}, 16^{\circ} \mathrm{E}\right)$ derived from $\mathrm{MF}$ radar data (top panel), and of the zonal mean zonal wind anomaly averaged between 60 and $90^{\circ} \mathrm{N}$ derived from CMAM30 data (bottom panel). (b) Hiccup composite of zonal mean temperature anomaly averaged between 60 and $90^{\circ} \mathrm{N}$ derived from CMAM30 data.

zonal mean temperature variation at $32 \mathrm{~km}$ centred around the hiccup onset, averaged over all 19 hiccups. This shows a similar behaviour to that seen in Fig. 1a for 2006, though of course smoothed out, with the temperature increasing after the hiccup onset day following a longer period of smoothly decreasing temperature in the stratosphere, before resuming its seasonal decrease after about 10 days.

Due to the small effects of a hiccup compared to those of a SSW, we cannot readily define anomalies from multi-year daily means since the latter are too noisy. Thus, we prepared the data as follows, before applying the superimposed epoch analysis:

1. a linear fit of atmospheric parameters over the autumn transition was prepared at each location;

2. the average linear fit was removed from each year;

3. the residual fields were averaged over non-hiccup years;

4. this average was then removed from each hiccup year to define the hiccup anomaly.

Non-hiccup years are those years between 1979 and 2013 that are not listed in Table 1. Please note that the resulting hiccup composites are statistically significant for values greater/lower than $\pm 1 \mathrm{~m} \mathrm{~s}^{-1}$ or $\mathrm{K}$.

\section{Results}

The hiccup composite of the zonal mean zonal wind deviation from the surface to $100 \mathrm{~km}$ and averaged from 60 to $90^{\circ} \mathrm{N}$ is shown in Fig. 3a, bottom panel. Although our selection criteria applies only at $32 \mathrm{~km}$, the hiccup, i.e. the decrease of the zonal mean zonal wind, occurs from the troposphere right up to the mesosphere. It appears that the decrease of the zonal wind begins in the troposphere and propagates upwards into the mesosphere within a few days, which would be consistent with the role of upward propagating SPWs. Before the onset of the hiccup, there is an increase of the zonal wind in the stratosphere. It is presumably this feature which allows the enhanced SPW propagation that causes the hiccup. Comparison of these results to the average behaviour of major SSWs show that both coupling processes are characterised by a wind weakening/reversal in the middle atmosphere (e.g. Limpasuvan et al., 2004; Matthias et al., 2013). However, while the hiccup seems to propagate upward, studies of Matthias et al. (2012) show an $\sim 4$ days earlier onset of the wind reversal in the mesosphere than in the stratosphere in composite analysis of major SSWs implying a downward propagation.

Figure 3a top shows the composite of the zonal wind at Andenes $\left(69^{\circ} \mathrm{N}, 16^{\circ} \mathrm{E}\right)$ in the mesosphere derived from local radar measurements. The decrease of the zonal wind is in good agreement with the mesospheric model results and thus corroborate them. However, there are differences between the observations and the model results. While the observations show a wave-like structure in the mesosphere especially before the onset of the hiccup, this structure does not occur in the CMAM30 data in the same way. These differences might occur because the model is free running above $1 \mathrm{hPa}$, because the composites include different years, or because the GW parametrisation scheme is not perfect. Note that we repeated the CMAM30 zonal mean wind analysis for an area around Andenes and got a similar behaviour of the hiccup as in the zonal mean (not shown). Thus, we omit the local version of Fig. 3a, bottom panel, and compare qualitatively the zonal mean model fields with the local observations.

The hiccup composite of the zonal mean temperature deviation from the surface to $100 \mathrm{~km}$ and averaged from 60 to $90^{\circ} \mathrm{N}$ is shown in Fig. 3b. The hiccup is characterised as a warming in the troposphere and stratosphere, and a cooling in the mesosphere. The temperature changes seem to lag the wind changes by a few days in the middle atmosphere. (They need not be synchronous, despite thermal-wind balance, because they are at the same latitude.) As was observed for the zonal wind, the temperature changes seem to propagate upward from the troposphere into the mesosphere within a few days, and there is a localised cooling in the stratosphere immediately before the hiccup (consistent with the strengthened zonal wind just before the onset day). Both the zonal wind and temperature show a downward-moving structure in the mesosphere from about day 10 onwards. Com- 


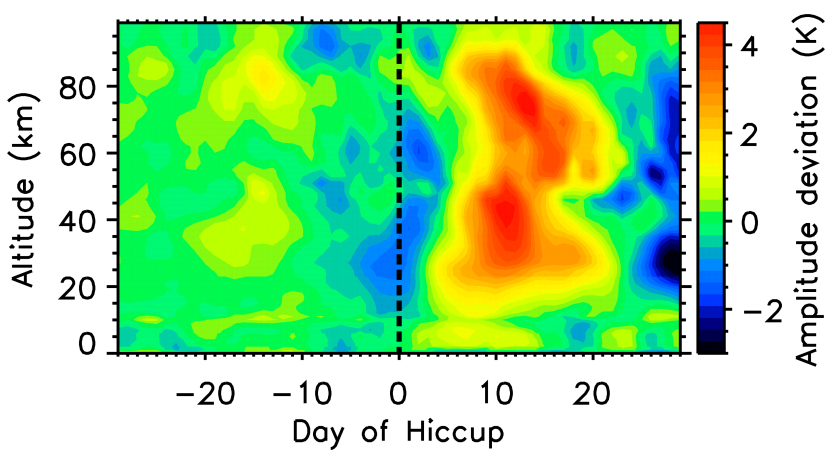

Figure 4. Hiccup composite of the PW 1 anomaly averaged from 60 to $90^{\circ} \mathrm{N}$ centred around the hiccup onset day and derived from CMAM30 data.

parison of these results to the average behaviour of SSWs shows that the temperature variations in the middle atmosphere are very similar in hiccups and in SSWs. Thus hiccups can be considered as "mini SSWs". However, as was the case with the zonal wind, it seems that there is an upward propagation of the temperature changes during the hiccup while Limpasuvan et al. (2004) observed a downward propagation of the temperature anomalies during SSWs. These differences might arise because while SPW propagation is not suppressed during hiccups, it is suppressed during SSWs (Hitchcock et al., 2013), allowing downward-propagating wavemean flow interaction to occur (Hitchcock and Shepherd, 2013).

Figure 4 shows the composite of PW 1 amplitude deviation centred around the hiccup onset day from the surface to $100 \mathrm{~km}$ and averaged from 60 to $90^{\circ} \mathrm{N}$. During the hiccup the composite shows a strong increase in the PW 1 amplitude throughout the lower and middle atmosphere. The decrease in PW 1 amplitude in the stratosphere just before the hiccup onset day is presumably the precursor anomaly that leads to the positive zonal wind anomaly seen in Fig. 3a, bottom panel. Comparing these results to the average behaviour of PW 1 around SSWs (e.g. Pancheva et al., 2009; Matthias et al., 2012) we determine that during both events the amplitude of PW 1 is increased throughout the middle atmosphere. However, while the amplitude of PW 1 is high before a SSW (e.g. Matthias et al., 2012), it is very low before the hiccup. Part of this difference is caused by the difference in definition of the onset day - SSWs are defined after a period of zonal-wind decline, while we have defined the hiccup onset day to be before the period of zonal-wind decline - but part of the difference suggests that to initiate a hiccup, a precursor anomaly is required.

\section{Discussion}

Our study was inspired by the first report of a perturbation of the autumn transition by Taylor et al. (2001). They observed

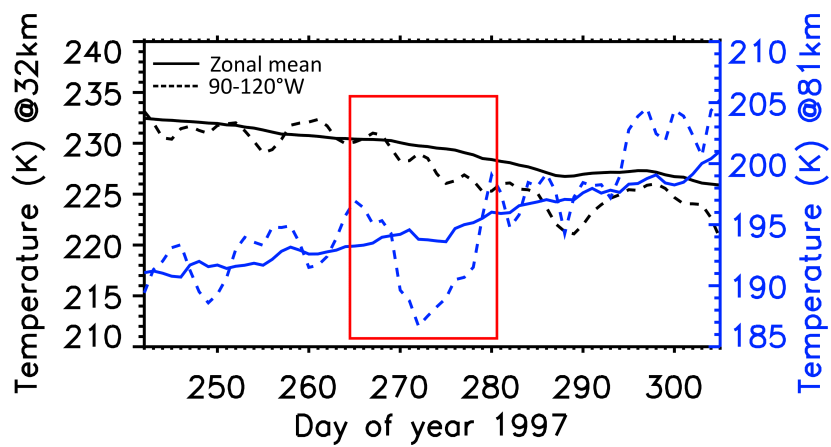

Figure 5. Temporal development of the temperature at $32 \mathrm{~km}$ (black) and $81 \mathrm{~km}$ (blue) averaged between 35 and $45^{\circ} \mathrm{N}$ of the autumn transition in 1997. The solid line represents the zonal mean and the dashed line the area around Ft. Collins $\left(90-120^{\circ} \mathrm{W}\right)$. The data are derived from CMAM30.

a decrease of the mesospheric temperature of up to $23 \mathrm{~K}$ in Ft. Collins $\left(41^{\circ} \mathrm{N}, 105^{\circ} \mathrm{W}\right)$ in the autumn transition of 1997 from day 260 to 280 . However we did not identify a hiccup in 1997 (cf. Table 1). To examine whether this mid-latitude perturbation nevertheless acts like a hiccup, Fig. 5 shows the temporal development of the CMAM30 temperature averaged from 35 to $45^{\circ} \mathrm{N}$ at $32 \mathrm{~km}$ (black) and $81 \mathrm{~km}$ (blue), similarly as in Fig. 1a. The solid lines represent zonal mean values, and the dashed lines averages around Ft. Collins (90$\left.120^{\circ} \mathrm{W}\right)$. The CMAM30 temperature shows a strong cooling in the mesosphere around Ft. Collins between day 260 and 280 (red rectangle), which is in good agreement with Taylor et al. (2001). There is a much smaller cooling in the zonal mean, suggesting that in the model the cooling over Ft. Collins is associated with a strong PW 1 magnitude but not with a zonal-mean circulation anomaly, as we have argued must be the case for a hiccup. The time period of occurrence of the small zonal-mean cooling is in agreement with the climatological zonal mean studies of WINDII temperatures between 35 and $45^{\circ} \mathrm{N}$ at $87 \mathrm{~km}$ by M. G. Shepherd et al. (2004), but we cannot use this version of the CMAM to examine behaviour at such high altitudes. In contrast to the high latitude hiccup seen in Fig. 1a, the stratospheric temperature of the mid latitude perturbation shows no warming during the time period of the mesospheric cooling, neither in the zonal mean nor in the regional temperature development shown in Fig. 5. Thus, the 1997 mid latitude perturbation seems to occur only at mesospheric heights, while the hiccup is a stratosphere-mesosphere coupling process.

Another indication that there are two distinct types of perturbations to the middle atmosphere during the autumn transition, differing in their latitudinal structure, comes from Manson et al. (2002) who studied the average seasonal variation of the zonal wind over Saskatoon $\left(52^{\circ} \mathrm{N}, 107^{\circ} \mathrm{W}\right)$ from year 1991 to 1998 in the MLT. Manson et al. (2002) show a wind reversal to westward winds from day 260 to 290, which agrees with the observations of Taylor et al. (2001) and 


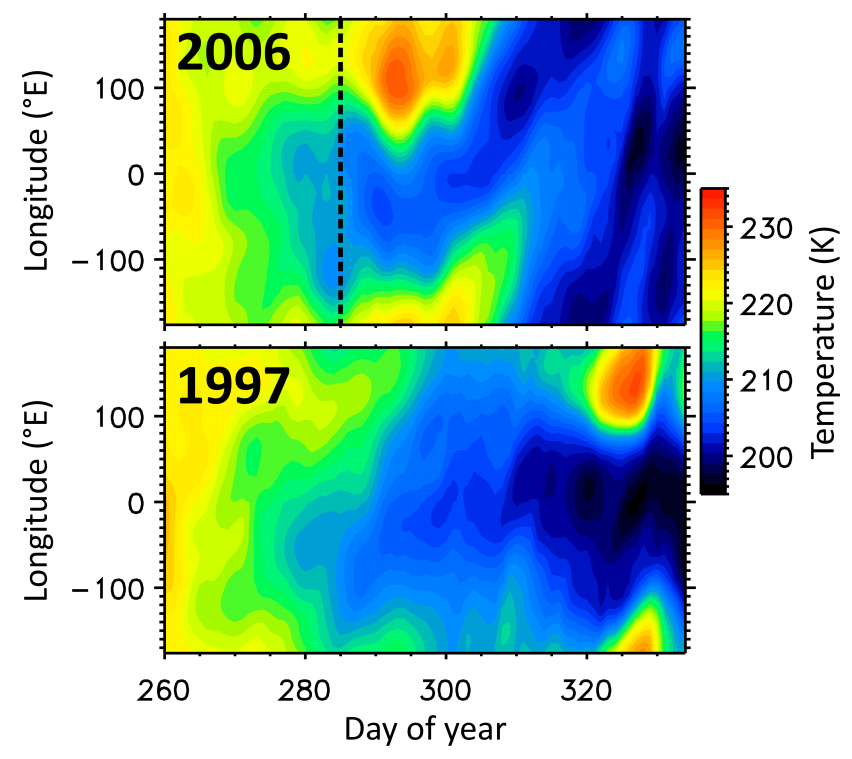

Figure 6. Temporal development of the longitudinal temperature pattern at $32 \mathrm{~km}$ in 2006 (top) and 1997 (bottom) averaged between 60 and $90^{\circ} \mathrm{N}$. The vertical dashed line in 2006 marks the hiccup onset day. The data are derived from CMAM30.

M. G. Shepherd et al. (2004), and a second reversal starting at day 300 , which is in agreement with our hiccup definition in this time period. The Saskatoon observations are located far enough north to see hiccups (cf. Fig. 1b), but not so far north to miss the mesospheric perturbations at mid latitudes. High latitude observations of Espy and Stegman (2002) at Stockholm $\left(59^{\circ} \mathrm{N}, 18^{\circ} \mathrm{E}\right)$ from year 1991 to 1998 on average show a decrease of the mesospheric temperature from day 290 to 320 , which is also in agreement with our observations of hiccups in this time period.

A possible cause for the mesospheric temperature perturbation of the autumn transition was first advanced by Liu et al. (2001), and more recently by Stray et al. (2014). Liu et al. (2001) argue that PW 1 transience, in both amplitude and phase, associated with the weak (but rapidly changing) zonal winds during the autumn transition can lead to large variability in local temperature measurements at mid and high latitudes. Liu et al. (2001) support their hypothesis with nudged TIME-GCM simulations of the 1997 autumn transition, which qualitatively (though not quantitatively) account for the mesospheric temperature perturbation observed by Taylor et al. (2001). In agreement with Liu et al. (2001), Stray et al. (2014) found a clear enhancement of the PW amplitude in the MLT in the composite (2000-2008) during autumn equinox using SuperDARN radars. As noted above, however, the 1997 event is not a hiccup according to our definition, and enhanced PW amplitudes at mesospheric heights appear to be a distinct phenomenon from the hiccup in the stratospheric zonal wind transition and its mesospheric echo.
Another attempt to explain perturbations to the autumn transition was presented by Espy and Stegman (2002). They assumed that the perturbation period coincides with the period when the atmosphere is virtually transparent to upward propagating GWs, and corroborated this hypothesis with a simple model of GW propagation with a constant flux of GWs throughout the year. The model results show that during the autumn transition, 75 to $90 \%$ of the GWs reach the MLT. Thus they argue that the mesospheric temperature perturbations around the autumn equinox result from combined effects of upward propagating PWs and GWs. We would not disagree with that conclusion but emphasise the need for a hiccup in the stratospheric zonal wind transition, associated with the onset of SPW propagation into the middle atmosphere, in order to initiate the distinctive stratospheremesosphere coupling seen in Fig. 1a.

Therefore we regard the hiccup as a distinct phenomenon from that discussed by Liu et al. (2001). Nevertheless, enhanced PW 1 amplitudes are an essential part of hiccups (needed to initiate the weakening of the stratospheric highlatitude zonal wind). As a further means of distinguishing the two phenomena, we may consider the PW 1 phase. Liu et al. (2001) state that changes of the PW 1 phase also cause the variability of the mesospheric temperature, but clearly, changes in phase can have no effect on the zonal mean. Therefore we considered the temporal development of the longitudinal temperature pattern at $32 \mathrm{~km}$ for all 35 years. Figure 6 illustrates this pattern for the non-hiccup autumn transition in 1997 and for the hiccup transition in 2006. We find that the phase of the temperature wave 1 pattern is stable for about 10-15 days during most of the hiccup events, while it can change rapidly during autumn transitions without a hiccup. This makes physical sense since hiccups are essentially a delay, or hiatus, in the autumn transition, during which the zonal wind is comparatively stable. Thus, while the rapidly changing PW 1 phase can certainly induce dramatic mesospheric temperature perturbations over particular longitudes, as argued by Liu et al. (2001), these are to be distinguished from high-latitude hiccup events.

\section{Conclusions}

We have identified a novel high-latitude stratospheremesosphere coupling process, called a hiccup, which is responsible for some of the distinctive mesospheric temperature perturbations seen in observations during the autumn transition. The hiccup is fundamentally defined in the stratospheric high-latitude zonal wind, where it originates from the onset of SPW propagation into the middle atmosphere as the zonal winds become westerly during the autumn transition, leading to a sudden dynamical weakening of the stratospheric winds before they eventually resume their overall strengthening. Thus it is like a "mini SSW", albeit with a distinctively smaller magnitude. The availability of the CMAM30 data 
set, covering a 30-year period, provides an opportunity to characterise the average properties of hiccups throughout the middle atmosphere, which according to our definition occur on average every second year. As with SSWs, there is a coherent response through the depth of the middle atmosphere, with polar warming in the stratosphere and simultaneous polar cooling in the mesosphere, and a zonal mean zonal wind weakening in the stratosphere and mesosphere. However, the temperature and zonal wind changes associated with a hiccup seem to propagate upward, rather than downward as is observed for major SSWs by e.g. Matthias et al. (2012). This is argued to result from the fact the SPW propagation is not completely suppressed following hiccups, as it is for SSWs, and thus the middle atmosphere continues to be driven from the troposphere during hiccups.

Although enhanced PW 1 amplitudes are an inherent element of hiccups, hiccups are zonal-mean perturbations and are thus to be distinguished from local PW variations as discussed by Liu et al. (2001). Hiccups seem to dominate at high latitudes, and non-hiccup PW variations at mid latitudes. More study of these interesting events during the autumn transition would seem to be warranted, using global analysis data sets such as CMAM30 in conjunction with groundbased and satellite measurements.

Acknowledgements. We would like to thank the Canadian Space Agency who funded the CMAM30 project, and Environment Canada who provided the supercomputing support. We also want to thank Ralph Latteck and Werner Singer for their permanent support using the MF radar at Andenes. We acknowledge the Global Modeling and Assimilation Office (GMAO) and the GES DISC for the dissemination of MERRA. We thank the two reviewers for their constructive comments.

Topical Editor C. Jacobi thanks two anonymous referees for their help in evaluating this paper.

\section{References}

Andrews, D. G., Holton, J. R., and Leovy, C. B.: Middle atmosphere dynamics, Academic Press, 1987.

Charlton, A. J. and Polvani, L. M.: A New look at stratospheric sudden warmings, Part I: Climatology and modeling Benchmarks, J. Climate, 20, 470-488, doi:10.1175/JCLI3994.1, 2007.

Charney, J. G. and Drazin, P. G.: Propagation of planetary-scale disturbances from the lower into the upper atmosphere, J. Geophys. Res., 66, 83-109, doi:10.1029/JZ066i001p00083, 1961.

de Grandpré, J., Beagley, S. R., Fomichev, V. I., Griffioen, E., McConnell, J. C., Medvedev, A. S., and Shepherd, T. G.: Ozone climatology using interactive chemistry: Results from the Canadian Middle Atmosphere Model, J. Geophys. Res., 105, 2647526491, doi:10.1029/2000JD900427, 2000.

Espy, P. and Stegman, J.: Trends and variability of mesospheric temperature at high-latitudes, Phys. Chem. Earth, Parts A/B/C, 27, 543-553, doi:10.1016/S1474-7065(02)00036-0, http://www. sciencedirect.com/science/article/pii/S1474706502000360, 2002.
Hitchcock, P. and Shepherd, T. G.: Zonal-Mean Dynamics of Extended Recoveries from Stratospheric Sudden Warmings, J. Atmos. Sci., 70, 688-707, doi:10.1175/JAS-D-12-0111.1, 2013.

Hitchcock, P., Shepherd, T. G., and Manney, G. L.: Statistical Characterization of Arctic Polar-Night Jet Oscillation Events, J. Climate, 26, 2096-2116, doi:10.1175/JCLI-D-12-00202.1, 2013.

Holton, J. R.: The influence of gravity wave breaking on the general circulation of the middle atmosphere, J. Atmos. Sci., 40, 2497-2507, doi:10.1175/15200469(1983)040<2497:TIOGWB>2.0.CO;2, 1983.

Holton, J. R. and Alexander, M. J.: The role of waves in the transport circulation of the middle atmosphere, in: Atmospheric Science Across the Stratopause, edited by: Siskind, D. E., Eckermann, S. D., and Summers, M. E., vol. 123 of Geophys. Monogr. Ser., pp. 21-35, AGU, Washington, D.C., doi:10.1029/GM123p0021, 2000.

Limpasuvan, V., Thompson, D. W. J., and Hartmann, D. L.: The life cycle of the northern hemisphere sudden stratospheric warmings, J. Climate, 17, 2584-2596, doi:10.1175/15200442(2004)017<2584:TLCOTN>2.0.CO;2, 2004.

Liu, H.-L., Roble, R. G., Taylor, M. J., and Pendleton, W. R.: Mesospheric planetary waves at northern hemisphere fall equinox, Geophys. Res. Lett., 28, 1903-1906, doi:10.1029/2000GL012689, 2001.

Manson, A., Meek, C., Stegman, J., Espy, P., Roble, R., Hall, C., Hoffmann, P., and Jacobi, C.: Springtime transitions in mesopause airglow and dynamics: photometer and MF radar observations in the Scandinavian and Canadian sectors, J. Atmos. Solar-Terr. Phys., 64, 1131-1146, doi:10.1016/S13646826(02)00064-0, 2002.

Matsuno, T.: A dynamical model of the stratospheric sudden warming, J. Atmos. Sci., 28, 1479-1494, doi:10.1175/15200469(1971)028<1479:ADMOTS>2.0.CO;2, 1971.

Matthias, V., Hoffmann, P., Rapp, M., and Baumgarten, G.: Composite analysis of the temporal development of waves in the polar MLT region during stratospheric warmings, J. Atmos. Solar-Terr. Phys., 90-91, 86-96, doi:10.1016/j.jastp.2012.04.004, 2012.

Matthias, V., Hoffmann, P., Manson, A., Meek, C., Stober, G., Brown, P., and Rapp, M.: The impact of planetary waves on the latitudinal displacement of sudden stratospheric warmings, Ann. Geophys., 31, 1397-1415, doi:10.5194/angeo-31-13972013, 2013.

McLandress, C., Scinocca, J. F., Shepherd, T. G., Reader, M. C., and Manney, G. L.: Dynamical Control of the Mesosphere by Orographic and Nonorographic Gravity Wave Drag during the Extended Northern Winters of 2006 and 2009, J. Atmos. Sci., 70, 2152-2169, doi:10.1175/JAS-D-12-0297.1, 2013.

Miyahara, S., Yoshida, Y., and Miyoshi, Y.: Dynamic coupling between the lower and upper atmosphere by tides and gravity waves, J. Atmos. Solar-Terr. Phys., 55, 1039-1053, doi:10.1016/0021-9169(93)90096-H, 1993.

Nash, E. R., Newman, P. A., Rosenfield, J. E., and Schoeberl, M. R.: An objective determination of the polar vortex using Ertel's potential vorticity, J. Geophys. Res., 101, 9471-9478, doi:10.1029/96JD00066, 1996.

Pancheva, D., Mukhtarov, P., and Andonov, B.: Global structure, seasonal and interannual variability of the migrating semidiurnal tide seen in the SABER/TIMED temperatures (2002-2007), 
Ann. Geophys., 27, 687-703, doi:10.5194/angeo-27-687-2009, 2009.

Ren, S., Polavarapu, S. M., and Shepherd, T. G.: Vertical propagation of information in a middle atmosphere data assimilation system by gravity-wave drag feedbacks, Geophys. Res. Lett., 35, doi:10.1029/2007GL032699, 2008.

Rienecker, M. M., Suarez, M. J., Gelaro, R., Todling, R., Bacmeister, J., Liu, E., Bosilovich, M. G., D.Schubert, S., Kim, L. T. G.-K., Bloom, S., Chen, J., Collins, D., Conaty, A., da Silva, A., Gu, W., Joiner, J., Koster, R. D., Lucchesi, R., Molod, A., Owens, T., Pawson, S., Pegion, P., Redder, C. R., Reichle, R., Robertson, F. R., Ruddick, A. G., Sienkiewicz, M., and Woollen, J.: MERRA: NASA's Modern-Era Retrospective Analysis for Research and Applications, J. Climate, 24, 3624-3648, doi:10.1175/JCLI-D-11-00015.1, 2011.

Scinocca, J. F., McFarlane, N. A., Lazare, M., Li, J., and Plummer, D.: Technical Note: The CCCma third generation AGCM and its extension into the middle atmosphere, Atmos. Chem. Phys., 8, 7055-7074, doi:10.5194/acp-8-7055-2008, 2008.

Shepherd, G. G., Stegman, J., Espy, P., McLandress, C., Thuillier, G., and Wiens, R. H.: Springtime transition in lower thermospheric atomic oxygen, J. Geophys. Res., 104, 213-223, doi:10.1029/98JA02831, 1999.

Shepherd, M. G., Espy, P., She, C., Hocking, W., Keckhut, P., Gavrilyeva, G., Shepherd, G., and Naujokat, B.: Springtime transition in upper mesospheric temperature in the northern hemisphere, J. Atmos. Solar-Terr. Phys., 64, 1183-1199, doi:10.1016/S13646826(02)00068-8, 2002.

Shepherd, G. G., Stegman, J., Singer, W., and Roble, R. G.: Equinox transition in wind and airglow observations, J. Atmos. Solar-Terr. Phys., 66, 481-491, doi:10.1016/j.jastp.2004.01.005, 2004.
Shepherd, M. G., Rochon, Y., Offermann, D., Donner, M., and Espy, P.: Longitudinal variability of mesospheric temperatures during equinox at middle and high latitudes, J. Atmos. Solar-Terr. Phys., 66, 463-479, doi:10.1016/j.jastp.2004.01.036, dynamics and Chemistry of the MLT Region - PSMOS 2002 International Symposium, 2004.

Singer, W., Keuer, D., and Eriksen, W.: The ALOMAR MF Radar: Technical Design and First Results, in: European Rocket and Balloon Programmes and Related Research, edited by: KaldeichSchürmann, B., vol. 397 of ESA Special Publication, pp. 101104, 1997.

Siskind, D. E., Coy, L., and Espy, P.: Observations of stratospheric warmings and mesospheric coolings by the TIMED SABER instrument, Geophys. Res. Lett., 32, L09804, doi:10.1029/2005GL022399, 2005.

Stegman, J., Murtagh, D., and Witt, G.: Extremes of oxygen airglow intensity, Eos Trans, 73, 14, 1992.

Stray, N. H., de Wit, R. J., Espy, P. J., and Hibbins, R. E.: Observational evidence for temporary planetary wave forcing of the MLT during fall equinox, Geophys. Res. Lett., 41, 6281-6288, doi:10.1002/2014GL061119, 2014.

Taylor, M. J., Pendleton, W. R., Liu, H.-L., She, C. Y., Gardner, L. C., Roble, R. G., and Vasoli, V.: Large amplitude perturbations in mesospheric $\mathrm{OH}$ Meinel and $87-\mathrm{Km}$ Na lidar temperatures around the autumnal equinox, Geophys. Res. Lett., 28, 1899-1902, doi:10.1029/2000GL012682, 2001.

Wunch, D., Tingley, M. P., Shepherd, T. G., Drummond, J. R., Moore, G., and Strong, K.: Climatology and predictability of the late summer stratospheric zonal wind turnaround over Vanscoy, Saskatchewan, Atmosphere-Ocean, 43, 301-313, doi:10.3137/ao.430402, 2005. 